\title{
Improving prognosis following a first variceal haemorrhage over four decades
}

\author{
P A McCormick, C O’Keefe
}

\begin{abstract}
Background-Variceal bleeding is a frequent cause of death in patients with cirrhosis and portal hypertension. Over the past 40 years a number of new techniques have been introduced to control active variceal haemorrhage. Many randomised controlled trials were performed to evaluate these new therapies. While most have demonstrated efficacy in controlling haemorrhage few showed im-
\end{abstract} proved survival.

Aim-The aim of this study was to investigate whether the prognosis for cirrhotic patients following a first variceal haemorrhage has improved over the past four decades.

Patients and methods-A total of 1475 patients included in the control or untreated arms of randomised controlled prophylactic trials for the primary prevention of variceal haemorrhage between 1960 and 2000. Twenty eight eligible randomised controlled studies were included. Over the 40 year period of observation there was a reduction in bleeding related mortality over time from approximately $65 \%$ to approximately $40 \%(p=0.024)$.

Conclusion-This study suggests that there has been a significant reduction in bleeding related mortality in patients with cirrhosis and portal hypertension over the past 40 years.

(Gut 2001;49:682-685)

Keywords: portal hypertension; cirrhosis; variceal bleeding; primary prophylaxis; prognosis

Variceal bleeding is one of the most frequent causes of death in patients with cirrhosis and portal hypertension. ${ }^{1}$ Approximately 30-50\% of cirrhotic patients die within six weeks of a first variceal bleed.${ }^{12}$ Over the past 40 years a number of new surgical, pharmacological, endoscopic, and radiological techniques have been introduced to improve the treatment of variceal bleeding. A large number of high quality randomised controlled trials have investigated the efficacy of these new treatment modalities. ${ }^{3}$ Many treatments for active variceal haemorrhage have been shown to arrest bleeding or prevent rebleeding, but few claimed to demonstrate improved survival. ${ }^{3}$ To look at this problem from another viewpoint, we hypothesised that the fate of the control groups in prophylactic trials should reflect the efficacy of contemporaneous treatment for acute variceal bleeding. Prophylactic trials spanning four decades are available and in many cases are of high quality. It is assumed that as participants in controlled trials these patients should have received "state of the art" treatment to arrest haemorrhage. The aim of this study was to determine whether bleeding related mortality changed over the period of observation.

\section{Methods}

Prophylactic trials were identified from literature searches using the Medline database. Studies were also identified from previous reviews, meta-analyses, etc. Studies of the natural history of varices were also reviewed in an attempt to identify well described untreated cohorts of patients. Trials were included if there was a placebo or untreated control group and sufficient information provided in the study to calculate mortality due to bleeding. For each study the number of patients in the control groups was identified. The number of patients in the control group who bled from varices or portal hypertensive causes and the number in whom death was attributed to bleeding were recorded. The severity of the underlying liver disease at the time of randomisation was recorded using Child's or Pugh's grading systems. ${ }^{56}$

\section{STATISTICS}

Results were analysed using GraphPad Prism (GraphPad software Inc, California, USA). Linear regression with $95 \%$ confidence intervals was graphed using GraphPad Prism. Differences in bleeding related mortality were assessed using Fisher's exact test. p values $<0.05$ were considered significant. Unless otherwise stated, data are expressed as mean (SEM).

\section{Results}

Twenty eight studies were identified. A number of studies published in abstract form were excluded because of insufficient data to calculate bleeding related mortality in the control groups..$^{711}$ Studies of the natural history of oesophageal varices were also reviewed but excluded for similar reasons. ${ }^{12-14}$ Details of the included studies are shown in table 1 . A total of 3105 patients were included, of whom 1475 were in the control groups. The mean number of patients in the control group per study was 52.7 (5). Pugh's or Child's grading was not available in seven studies but was estimated from data supplied in the papers. ${ }^{15-21}$ Pugh's grade at entry to the studies was as follows: 502 grade A (34\%), 596 grade B (40\%) and 377 grade C $(26 \%)$. Mortality rates ranged from $26 \%$ to $83 \%$. The relationship between time and mortality is shown in fig 1 . An $F$ test showed that there was a significant fall in 
Table 1 Summary of prophylactic trials included in this analysis

\begin{tabular}{|c|c|c|c|c|}
\hline Trial & (n) & $\begin{array}{l}\text { Pugh's grade } \\
A / B / C\end{array}$ & Mortality & Treatment for bleeding \\
\hline Jackson $1968^{\star 17}$ & 58 & $10 / 23 / 25$ & $55 \%$ & $S^{\star}$ \\
\hline Resnick $1969^{\star 20}$ & 45 & $19 / 20 / 6$ & $42 \%$ & SS \\
\hline Conn $1972^{\star 15}$ & 31 & $10 / 11 / 10$ & $50 \%$ & Not stated \\
\hline Conn $1972^{\star 15}$ & 22 & $0 / 11 / 11$ & $83 \%$ & SS \\
\hline Paquet $1982^{30}$ & 36 & $9 / 11 / 16$ & $64 \%$ & "Active conservative" \\
\hline Witzel $1985^{31}$ & 53 & $19 / 25 / 9$ & $63 \%$ & Not stated \\
\hline Koch $1986^{32}$ & 30 & $16 / 9 / 5$ & $70 \%$ & Not stated \\
\hline Wordehoff $1987^{33}$ & 24 & $7 / 12 / 5$ & $53 \%$ & $\mathrm{VP}, \mathrm{BT}$ \\
\hline Pascal $1987 \star 18$ & 112 & $19 / 41 / 52$ & $60 \%$ & "Standard treatment" \\
\hline Sauerbruch $1988^{34}$ & 65 & $21 / 30 / 14$ & $46 \%$ & ES, VP, BT \\
\hline Piai $1988^{35}$ & 69 & $16 / 31 / 22$ & $66 \%$ & Som, ES, BT, S \\
\hline Lebrec $1988^{36}$ & 53 & $29 / 24 / 0$ & $50 \%$ & ES, VP, BT \\
\hline Ideo $1988^{37}$ & 49 & $19 / 19 / 11$ & $36 \%$ & Som, BT \\
\hline Santangelo $1988^{\star 21}$ & 45 & $12 / 17 / 16$ & $29 \%$ & Not stated \\
\hline Potzi $1989^{38}$ & 41 & $14 / 14 / 13$ & $64 \%$ & ES \\
\hline IMPP $1989^{39}$ & 89 & $56 / 28 / 5$ & $32 \%$ & Drugs, ES, BT \\
\hline Russo $1989^{40}$ & 20 & $9 / 8 / 3$ & $67 \%$ & BT, ES \\
\hline Inokuchi $1990^{41}$ & 52 & $31 / 21 / 0$ & $41 \%$ & ES, S \\
\hline Kobe $1990^{42}$ & 33 & $10 / 17 / 6$ & $58 \%$ & $\mathrm{ES}$ \\
\hline Andreani $1990^{43}$ & 41 & $10 / 21 / 10$ & $40 \%$ & VP, BT \\
\hline Triger $1991^{44}$ & 35 & $14 / 15 / 6$ & $29 \%$ & ES \\
\hline De Franchis $1991^{45}$ & 51 & $18 / 22 / 11$ & $65 \%$ & ES \\
\hline Conn $1991^{46}$ & 51 & $24 / 24 / 3$ & $27 \%$ & VN, ES \\
\hline Gregory $1991^{47}$ & 138 & $43 / 59 / 36$ & $32 \%$ & VP, BT, SS \\
\hline PROVA $1991^{\star 19}$ & 72 & $21 / 22 / 29$ & $46 \%$ & ES \\
\hline Sarin $1996^{48}$ & 33 & $10 / 13 / 10$ & $38 \%$ & EVL, ES \\
\hline Lay $1997^{49}$ & 64 & $16 / 23 / 25$ & $26 \%$ & Drugs, ES, BT, S \\
\hline Lo $1999^{50}$ & 63 & $20 / 25 / 18$ & $32 \%$ & VP, EVL \\
\hline
\end{tabular}

* Studies in which Pugh's grading was not given but was estimated from data in original publication.

Emergency treatment for variceal bleeding included: ES, endoscopic sclerotherapy; EVL, endoscopic variceal band ligation; BT, balloon tamponade; SS, shunt surgery; S, surgery; Som, somatostatin; VP, vasopressin; VN, vasopressin+nitroglycerin; $S^{\star}$, transoesophageal ligation of varices in a minority of patients—-details of other treatments not given.

bleeding related mortality with an $\mathrm{F}$ value of 5.57 and $p=0.026$. From the regression line it appears that overall mortality fell from approximately $55 \%$ to approximately $40 \%$ over the 40 year period of observation.

Further analysis by decade was carried out due to concerns about the distribution of the numbers of studies, which ranged from only four in the 1960s and 1970s to 13 in the 1980 s and 11 in the 1990s. Mortality in the 1990s was significantly lower than that in the 1980s ( $\mathrm{p}=$ 0.0055 ) but not significantly different to the 1960 s and 1970s $(\mathrm{p}=0.12)$.

\section{Discussion}

The results of this analysis suggest that mortality from a first variceal haemorrhage in cirrhotic patients has declined over the past 40 years by approximately a third. Many new treatments and techniques have been introduced over this period, including somatostatin,

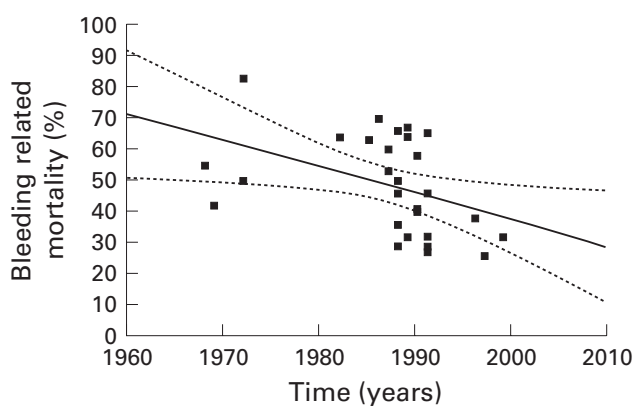

Figure 1 Percentage mortality for patients who bled in the control arms of prophylactic trials over the 40 years, 1960-2000. Bleeding related mortality declined significantly over time, $p=0.026$. The slope of the regression line is $-0.85 \pm 0.36$ with $r=-0.42$. octreotide, terlipressin, endoscopic sclerotherapy, endoscopic banding, transjugular intrahepatic portosystemic stent shunt, advances in surgical techniques, etc.$^{3}$ Advances in intensive care and increasing recognition of the importance of bacterial infections and early appropriate treatment may also help to improve prognosis. ${ }^{22}$ There is a long tradition of clinical trials in portal hypertension. With standardisation in terminology and methods of reporting many portal hypertension trials are now recognised to be of particularly high quality. ${ }^{23}$ Most clinical trials have shown that these new techniques improve control of active variceal haemorrhage and reduce transfusion requirements. With rare exceptions, significant improvements in survival have not been demonstrated in controlled trials including patients with active variceal haemorrhage.

Many of the randomised trials in active variceal haemorrhage were not sufficiently large to demonstrate significant changes in mortality. The largest mortality occurs during the first haemorrhage. Many of the acute trials included patients with recurrent bleeding who tend to have a better prognosis, having already survived an episode of variceal haemorrhage. Patients with massive haemorrhage who die in the prehospital or early hospital phase are also often excluded from these trials. ${ }^{24}$ It is interesting that one of the few trials to claim improved survival studied emergency treatment started in the prehospital phase. ${ }^{4}$ The relative exclusion of many of these high risk patients may partly explain the difficulty in demonstrating improved survival in active bleeding trials. For this reason we chose to look at the control groups of randomised prophylactic trials. These control groups are as close to an ideal study group as we are likely to get. They received no treatment known to influence variceal haemorrhage and follow up is complete. As participants in clinical trials it is assumed that they received the "state of the art" treatment for variceal haemorrhage once bleeding started (table 1). Because they are first time bleeders they should have a high rate of bleeding related mortality. In addition, deaths from bleeding in the prehospital or early hospital phase are likely to be recorded. However, it is important to realise that these types of data describe overall bleeding related mortality and may reflect a number of factors in addition to treatment received. Other factors such as infection, presence of hepatoma, or portal vein thrombosis may have significant effects on overall mortality. ${ }^{22} 25$ These factors are likely to introduce heterogeneity into the results. Nevertheless, the fate of control groups in clinical trials should reflect the effectiveness of the best contemporary treatment available.

Although they are a nearly ideal study group the information available about the control groups is not complete. Standardisation in the reporting of clinical trials is a relatively recent phenomenon and heterogeneity is to be expected in studies reported over four decades. ${ }^{26}$ From the original papers it is not always clear whether bleeding related mortality refers to the first bleed or also includes subsequent 
recurrent bleeds over a variable period of follow up. Because of the success of prophylactic beta blockers, non-treated control groups in prophylactic trials may become unethical. Meta-analyses have confirmed that prophylactic beta blockers prevent variceal haemorrhage and improve survival. ${ }^{327}{ }^{28}$ Beta blockade has become the gold standard against which other prophylactic treatments must be compared. As a consequence it is unlikely that information on further large cohorts of untreated patients with portal hypertension will become available. It may not be possible to extend the current study into coming decades.

A recent study by El-Serag and Everhart lends support to our conclusion that prognosis for variceal haemorrhage has improved. ${ }^{29}$ Using the Veterans Affairs patient database they identified two large cohorts of patients treated for an initial variceal haemorrhage between 1981-82 (1339 patients) and 1988-91 (3636 patients). Mortality at 30 days declined from $29.6 \%$ to $20.8 \% \quad(p=0.0001)$. Interestingly, if the analysis was started 30 days after the initial bleed there was no long term difference in mortality. The authors thus concluded that improved survival was due to improvements in treatment of the initial bleed, most probably the widespread use of injection sclerotherapy. Treatments such as liver transplantation had little impact on outcome as only 12 patients in the latter cohort received this treatment.

In conclusion, study of the control groups of prophylactic trials in portal hypertension suggests that the prognosis for patients with variceal haemorrhage has improved over the past four decades.

Part funded by a grant from the Irish Health Research Board. We would like to thank Deirdre Carey, Statistician, Departmen of Public Health, Eastern Regional Health Authority, for her help with this manuscript

1 D'Amico G, Luca A. Natural history. Clinicalhaemodynamic correlations. Prediction of the risk of haemodynamic correlations. Prediction of the risk

2 Burroughs AK. The natural history of varices. $f$ Hepatol 1993;17(suppl 2):S10-13.

3 D'Amico G, Pagliaro L, Bosch J. The treatment of portal hypertension: a meta-analytic review. Hepatology 1995;22: 332-57.

4 Levacher S, Letoumelin P, Pateron D, et al. Early administration of terlipressin plus glyceryl trinitrate to control active upper gastrointestinal bleeding in cirrhotic patients. Lancet 1995;346:865-8.

5 Child CG, Turcotte JG. Surgery and portal hypertension. In: Child CG, ed. The liver and portal hypertension. Philadelphia: WB Saunders and Co, 1964:50-1.

6 Pugh RN, Murray-Lyon M, Dawson JL, et al. Transection of the oesophagus for bleeding oesophageal varices. $\mathrm{Br} F$ Surg 1973;60:646-9.

7 Planas R, Boix J, Dominguez M, et al. Prophylactic sclerosis of esophageal varices (EV). Prospective trial. $\mathcal{F}$ Hepatol
of of esophageal varice

8 Fleig WE, Stange EF, Wordefoff D, et al. A randomized trial comparing prophylactic (PS) and therapeutic endoscopic sclerotherapy (TS) in cirrhotic patients with large esophageal varices and no previous hemorrhage. $\mathcal{f}$ Hepatol 1988;7(suppl 1):S128.

9 Colman J, Jones P, Finch C, et al. Propranolol in the prevention of variceal hemorrhage in alcoholic cirrhotic patients. Hepatology 1990;12:851

10 Strauss E, de Sa MFGaA, Lacet CMC, et al. A randomized controlled trial for the prevention of the first upper gastrointestinal bleeding due to portal hypertension in cirrhosis: sclerothrapy or propranolol versus control groups. Hepatol ogy 1988;8:1395.

11 Saggiore A, Pallini P, Chiozini G, et al. Prophylactic sclerotherapy: a controlled study. Dig Dis Sci 1986; 31(suppl):504S.

12 Baker LA, Smite C, Lieberman G. The natural history of esophageal varices. Am F Med 1959;26:228-37.
13 Lebrec D, Fleury P, Rueff B, et al. Portal hypertension, size of esophageal varices and risk of gastrointestinal bleeding in alcoholic cirrhosis. Gastroenterology 1980;79:1144.

14 Dagradi AE. The natural history of esophageal varices in patients with alcoholic liver cirrhosis. Am $\mathcal{F}$ Gastroenterol 1972;57:520-40.

15 Conn HO, Lindermuth WW, May CJ, et al. Prophylactic portocaval anastomosis: a tale of two studies. Medicine (Baltimore) 1972;51:27-40.

16 Conn HO, Lindermuth WW. Prophylactic portocaval anastomosis in cirrhotic patients with esophageal varices: a progress report of a continuing study. N Engl f Med 1965; 272:1255-63.

17 Jackson FC, Perrin EB, Smith AG, et al. A clinical investigation of the portacaval shunt: II survival analysis of the prophylactic operation. Am $\mathcal{F}$ Surg 1968;115:22-42.

18 Pascal J-P, Cales P, and a Multicenter Study Group. Propranolol in the prevention of first upper gastrointestinal tract hemorrhage in patients with cirrhosis of the liver and esophageal varices. $N$ Engl f Med 1987;317:856-61.

19 The PROVA study group. Prophylaxis of first hemorrhage from esophageal varices by sclerothreapy, propranolol or both in cirrhotic patients: a randomized multicenter trial. Hepatology 1991;14:1016-24.

20 Resnick RH, Chalmers TC, Ishihara AM, et al. A controlled trial of the prophylactic portacaval shunt.: a final report. Ann Intern Med 1969;70:675-88.

21 Santangelo WC, Dueno MI, Estes BL, et al. Prophylactic sclerotherapy of large esophageal varices. $N$ Engl f Med 1988;318:814-18.

22 Goulis J, Armonis A, Patch D, et al. Bacterial infection is independently associated with failure to control bleeding in cirrhotic patients with gastrointestinal hemorrhage. Hepatology 1998;27:1207-12.

23 Kjaergard LL, Nikolova D, Gluud C. Randomized clinical trials in hepatology: predictors of quality. Hepatology 1999; 30:1134-8.

24 Burroughs AK, Mezzanotte G, Phillips A, et al. Cirrhotic with variceal hemorrhage: the importance of the time interval between admission and the start of analysis for survival and rebleeding rates. Hepatology 1989;9:801-7.

25 Chen $\mathrm{CH}$, Sheu JC, Huang GT, et al. Characteristics of hepatocellular carcinoma presenting with variceal bleeding. $\mathcal{F}$ Gastroenterol Hepatol 1998;13:170-4.

26 Pagliaro L, De Franchis R. Where were we? A summary of the issues where consensus was reached at Baveno I. In: De Franchis R, ed. Portal hypertension II: Proceedings of the Second Baveno International Consensus Workshop on Definitions, Methodology and Therapeutic Strategies. Oxford: Blackwell Science Ltd, 1996:1-9.

27 Hayes PC, Davis JM, Lewis JA, et al. Meta-analysis of value of propranolol in prevention of variceal haemorrhage. Lancet 1990;336:153-6.

28 Poynard T, Cales P, Pasta L, et al. Beta-adrenergicantagonist drugs in the prevention of gastrointestinal bleeding in patients with cirrhosis and esophageal varices. N Engl F Med 1991;324:1532-8.

29 El-Serag HB, Everhart JE. Improved survival after variceal hemorrhage over an 11-year period in the Department of Veterans Affairs. Am 7 Gastroenterol 2000;95:3566-73.

30 Paquet KJ. Prophylactic endoscopic sclerosing treatment of the esophageal wall in varices - a prospective controlled randomized trial. Endoscopy 1982;14:4-5.

31 Witzel L, Wolbergs E, Merki H. Prophylactic endoscopic sclerotherapy of oesophageal varices: a prospective controlled study. Lancet 1985;1:773-5.

32 Koch $\mathrm{H}$, Henning $\mathrm{H}$, Grimm H, et al. Prophylactic sclerosing of esophageal varices - results of a prospective controlled study. Endoscopy 1986;18:40-3.

33 Wordehoff D, Spech HJ. Prophylaktische osophagusvarizensklerosierung. Dtsch Med Wochenschr 1987;112:947-51.

34 Sauerbruch T, Wotzka R, Kopcke W, et al. Prophylactic sclerotherapy before the first episode of variceal hemorsclerotherapy before the first episode of variceal hemor-
rhage in patients with cirrhosis. N Engl f Med 1988;319:815.

35 Piai G, Cipolletta L, Claar M, et al. Prophylactic sclerotherapy of high-risk esophageal varices; results of a multicentric prospective controlled trial. Hepatology 1988; 8:1495-500.

36 Lebrec D, Poynard T, Capron J-P, et al. Nadolol for prophylaxis of gastrointestinal bleeding in patients with cirrhosis: a randomized trial. F Hepatol 1988;7:118-25.

37 Ideo G, Bellati G, Fesce E, et al. Nadolol can prevent the first gastrointestinal bleeding in cirrhotics: a prospective, randomized study. Hepatology 1988;8:6-9.

38 Potzi R, Bauer P, Reichel W, et al. Prophylactic endoscopic sclerotherapy of oesophageal varices in liver cirrhosis: a multicentre prospective controlled randomisd trial in Vienna. Gut 1989;30:873-9.

39 The Italian Multicenter Project for Propranolol in Prevention of Bleeding. Propranolol prevents first gastrointestinal bleeding in non-ascitic cirrhotic patients. $\mathcal{F}$ Hepatol 1989;9: $75-83$.

40 Russo A, Giannone G, Magnano A, et al. Prophylactic sclerotherapy in nonalcoholic liver cirrhosis: preliminary results of a prospective controlled randomized trial. World $\mathcal{F}$ Surg 1989;13:149-53.

41 Inokuchi K, and Cooperative Study Group for Portal Hypertension of Japan. Improved survival after prophylactic portal nondecompression surgery for esophageal varices: a randomized clinical trial. Hepatology 1990;12:1- 
42 Kobe E, Zipprich B, Schentke K-U, et al. Prophylactic endoscopic sclerotherapy of esophageal varices-a prospective randomized trial. Endoscopy 1990;22:245-8.

43 Andreani T, Poupon RE, Balkau BJ, et al. Preventive therapy of first gastrointestinal bleeding in patients with cirrhosis: results of a controlled trial comparing propranolol, endoscopic sclerotherapy and placebo. Hepatology 1990;12: 1413-19.

44 Triger DR, Smart HL, Hosking SW, et al. Prophylactic sclerotherapy for esophageal varices: long-term results of a single-center trial. Hepatology 1991;13:117-23.

45 De Franchis R, Primignani M, Arcidiacono PG, et al. Prophylactic sclerotherapy in high-risk cirrhotics selected by endoscopic criteria. Gastroenterology 1991;101:1087-93.

46 Conn HO, Grace ND, Bosch J, et al. Propranolol in the prevention of the first hemorrhage from esophagogastric varices a mulicenter, randomised clinical trial. Hepatric 1991;13:902-12.
47 The Veterans Affairs Cooperative Variceal Sclerotherapy Group. Prophylactic sclerotherapy for esophageal varices in men with alcoholic liver disease: a randomized, singleblind, multicenter clinical trial. N Engl f Med 1991;324: 1779-84.

48 Sarin SK, Guptan RKC, Jain AK, et al. A randomized controlled trial of endoscopic variceal band ligation for primary prophylaxis of variceal bleeding. Eur f Gastroenterol Hepatol 1996;8:337-42.

49 Lay C-S, Tsai Y-T, Teg C-Y, et al. Endoscopic variceal ligation in prophylaxis of first variceal bleeding in cirrhotic patients with high-risk esophageal varices. Hepatology 1997;25:1346-50.

50 Lo G-H, Lai K-H, Cheng J-S, et al. Prophylactic banding ligation of high-risk esophageal varices in patients with cirrhosis: a prospective, randomized trial. 7 Hepatol 1999;31:451-6.

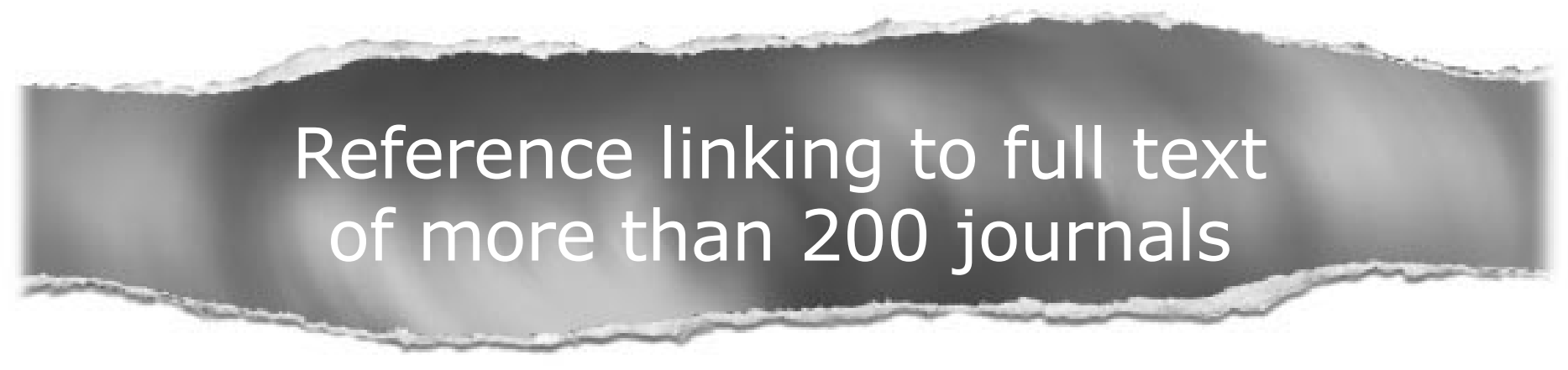

Toll free links

You can access the FULL TEXT of articles cited in Gut online if the citation is to one of the more than 200 journals hosted by HighWire (http://highwire.stanford.edu) without a subscription to that journal. There are also direct links from references to the Medline abstract for other titles.

www.gutjnl.com 